\title{
Inferences from Interest Rate Behavior for Monetary Policy Signaling
}

\author{
Suresh Ramanathan ${ }^{1}$, Kian-Teng Kwek \\ Department of Economics, Faculty of Economics and Administration, University of Malaya, Malaysia
}

\begin{abstract}
Weak mean reversion of interest rates towards the long term mean suggests high probability of agents in financial markets failing to interpret monetary policy signalling efficiently and financial market related interest rate unable to achieve equilibrium. Increased randomness penetrating interest rate markets is due to the weak monetary policy signalling effect which dilutes information flow from central banks' to agents in the financial market. In such cases the effectiveness monetary policy erodes as it departs from the objectives of central banks and financial regulators
\end{abstract}

Keywords: Vasicek, Cox Ingersoll Ross Interest rate models, Ornstein - Uhlenbeck process, Mean Reversion, Drift term

PACS: 02.50.Fz, 89.65.Gh

\section{Introduction}

In gauging financial market behavior, it is pertinent to be able to foresee the gap between turning point of financial market expectations on interest rates and the mean of short term interest rates. As this gap widens, the efficiency of price clearing in financial markets deteriorate. In interest rate markets, the dysfunctionality of interbank interest rates occurs when this gap widens. Two factors have been identified, the hoarding of financial market liquidity and the delay in response to a financial crisis by central banks and financial regulators. The hoarding of financial market liquidity paralyses the price clearing mechanism in financial markets and causes congestion in the interbank interest rate market. Acharya and Skeie (2011) find financial liquidity hoarding during GFC of 2008 distorting the term premia of interbank interest rate markets given the action by agents in financial market of perceiving and pricing in worsening of financial liquidity conditions. The hoarding of financial market liquidity increases when central banks and financial regulators delay their response in taming financial market volatility. A delayed response creates uncertainty in financial markets, further exacerbating the hoarding of financial liquidity.

The GFC of 2008 exposed the limitation of theoretical financial models in explaining financial market behavior. Financial models were at the heart of the crisis and these models failed in aiding the clearing of prices in interest rate markets. ${ }^{2}$. The inflexibility of pre GFC 2008 financial models in modeling financial market behavior and the underestimation of market and credit risk prior to the crisis contributed to the GFC of 2008. In the context of interest rate modeling post GFC 2008, the incorporation of financial market behavior gained importance. Single factor interest rate models have begun to include elements such as jumps, instantaneous volatility, waiting time and financial liquidity constraints. The inclusion of these elements in interest rate modeling is reflective of the importance of behavioral economics ${ }^{3}$. The significance of financial market behavior is due to the systematic changes that financial markets have experienced in the past two decades. These changes occurred in three major areas according to Szyska (2011), within financial institutions, organization and functioning of financial markets and among financial trading instruments. The GFC of 2008 and post crisis period witnessed the conflict between neo classical economics and behavioral economics in financial markets. Matters such as loss of financial market liquidity, counterparty risk in financial trading, increased volatility and sharp devaluation of asset values in the space of financial market trading were better understood in the context of behavioral economics than neo classical economics. The emergence of behavioral economics in explaining financial market anomalies made this offshoot of economics a popular area of research. The key difference

${ }^{1}$ Corresponding Author, email: skrasta70@hotmail.com.

${ }^{2}$ WSJ - January 22 2010 - WSJ's Scott Patterson reports, in his book 'The Quants 'developed complex systems to trade securities such as mortgage derivatives, which were at the heart of the crisis

\footnotetext{
${ }^{3}$ Behavioral economics and its related area of study, behavioral finance, use social, cognitive and emotional factors in understanding the economic decisions of individuals and institutions that are performing economic functions. It is primarily concerned with the bounds of rationality of economic agents. See Ashraf, Camerer and Loewenstein (2005).
} 
between neo classical economics and behavioral economics is the assumption on rationality of investors under neo classical economics. This assumption failed during GFC of 2008 resulting in behavioral economics taking precedence in the approach of interest rate modeling.

With the approach in interest rate modeling using the tools of behavioral economics, Tak (2010) used a modified version of single factor interest rate model of Vasicek by applying the Markovian regime switching jump diffusion method. The parameters for speed of interest rate mean reversion and the intensity of interest rate volatility were allowed to switch over time in a continuous manner. The model incorporated dynamics of interest rate behavior and cyclical nature of interest rate time series that was applied onto prices of bonds. The approach provided inference on how an alternative single factor interest rate model is used to capture jump diffusions and dynamics of interest rates changes. The model was of particular use in capturing financial market anomalies that occurred during the GFC of 2008 period.

In modeling interest rate volatility, Zeytun and Gupta (2007) compared the instantaneous volatility factor between Cox Ingersoll Ross model and the Vasicek model and find that the Vasicek model overestimates jumps while the Cox Ingersoll Ross model works well when interest rates are high instead of a low interest rate environment. This occurrence is due to the ability of the Vasicek model capturing negative interest rate situations. The interest rate models however react similarly when instantaneous volatility parameters were changed but in the case of the Cox Ingersoll Ross model, the change in instantaneous volatility parameter did not affect prices of bonds as intense as in the Vasicek model. The ability of the Vasicek model to capture negative interest rate is significant since it reflects the risk of financial market related interest rates moving towards negative territory ${ }^{4}$ particularly when policy interest rates are at zero bound levels The information on behavior of instantaneous volatility parameter were useful in designing financial strategies against interest rate risk, giving financial markets certainty with symmetric information on monetary policy

In enhancing the capability of single factor interest rate models that incorporate behavioral economics tool, Zoubi (2009) identified the drift function for mean reversion of interest rates as beneficial. The function captures expected instantaneous change in the interest rate at time $t$. The drift function and instantaneous volatility parameters complement each other in designing optimal financial market strategies to hedge against interest rate risk. The overall goodness of fit for single factor interest rate models were noted to improve when the drift function was included compared to interest rate models that do not have the drift function for mean reversion of interest rates. Further evidence of financial market anomalies that developed during GFC of 2008 includes waiting time and financial market liquidity constraints. These market anomalies made available conditions for trading arbitrage to develop given the asymmetrical financial market information that existed. In order to capture the behavior of interest rates under those circumstances, continuous stochastic models using a modified Ornstein - Uhlenbeck ${ }^{5}$ stochastic process were identified as appropriate. Janczura, Orzel and Wylomanska (2011) used this approach to model waiting period and financial market liquidity in the interbank market of interest rates of Emerging Europe. The Ornstein -Uhlenbeck process in their approach used a stable distribution and sub-diffusion system that demonstrated the behavior of interest rates using the Fokker Planck ${ }^{6}$ equation. The process reflected low financial liquidity situation in constant periods and heavy tailed risk behavior.

The significance of financial market behavior during GFC 2008 and the post crisis period is that it had introduced a different approach in modeling interest rate markets. Anomalies in financial markets and the risk of

\footnotetext{
${ }^{4} 12^{\text {th }}$ December 2012 - Financial Times - 'Investors eye possible negative ECB rates' -Growing expectations that the European Central Bank (ECB) will attempt to boost Eurozone growth prospects by charging banks for using its deposit facility have started to be reflected in market interest rates. The interest rate on borrowing unsecured cash for one year in EURO wholesale markets dipped below zero for the first time after the ECB last week downgraded steeply its 2013 Eurozone growth forecasts.
}

$27^{\text {th }}$ December 2012 - Reuters- -'January Treasury bill interest rates turn negative' - The interest rate on Treasury -bills due January $10^{\text {th }}$ was quoted at minus 0.5 basis point, down half a basis point from late on Wednesday while the bill issue due the following week was quoted at minus 0.25 basis point, down 1.5 basis points,

\footnotetext{
5 The Ornstein - Uhlenbeck process. It is named after Leonard Ornstein and George Eugene Uhlenbeck. It is a stochastic process that describes the velocity of Brownian particle under the influence of friction. The process is stationary, Gaussian and Markovian that satisfies these three conditions, allowing linear transformations of the space and time variables (see Doob, J.L 1942). Over time the process tends to drift towards its long term mean, which is called mean reverting. The process can be considered to be a modification of the random walk in a continuous time or Weiner process in which the properties of the process have been changed so that there is a tendency of the walk to move back towards a central location, with a greater attraction when the process is further away from the centre. The Ornstein-Uhlenbeck process can also be considered as the continuous time analogue of the discrete time auto regressive AR (1) process.

${ }^{6}$ The Fokker-Planck equation describes the time evolution of the probability density function of the velocity of a particle and cane be generalized to other observables also. It is named after Adrian Fokker and Max Planck.
} 
negative interest rates were researched in the context of behavioral economics that requires policy solutions that are tailored accordingly.

This paper conceptualizes single factor mean reversion interest rate models of Vasicek and Cox Ingersoll Ross to identify mean reversion of interest rates, instantaneous volatility in Emerging Asia (EA) interest rate markets and the negative drift term in Vasicek and Cox Ingersoll Ross models. The objective being to capture the behavior of financial market related interest rates that would serve as a useful tool for monetary policy signaling.

\section{The Model}

The modeling of imperfection in EA interest rate markets uses two single factor mean reversion interest rate models, the Vasicek and Cox Ingersoll Ross. While advanced interest rate models ${ }^{7}$ have been applied for derivatives pricing and gauging impact of monetary policy in financial markets, the appropriateness of using the single factor mean reversion interest rate model in this study suits with the assumption that EA economies interest rate markets are at a developing stage. The initial steps in modeling imperfection of interest rate markets of EA is by identifying the period of study which is from $2^{\text {nd }}$ June 2008 to $30^{\text {th }}$ September $2011^{8}$, consisting three years and three months. The policy interest rates for each EA economies are identified at the beginning of the study period ${ }^{9}$.

The second step involves estimating the mean of short term interest rates that is used as the underlying instrument in both the single factor mean reversion interest rate models, the speed of mean reversion and the instantaneous volatility. The short term interest rate that is used in this exercise is the 3 month by 3 month forward starting swaps. The sensitivity of this financial instrument to monetary policy changes, short duration tenor and features that incorporate financial market expectations impart valuable information to agents in financial market place. Forward starting swaps is not similar to interbank offered rates which have a daily fixing feature that is averaged by central banks and financial regulators and therefore not reflecting financial market expectations accurately. In the case of forward starting swaps, the interest rate equilibrium for this financial trading instrument is determined by agents in the interest rate market, thus giving it a market driven flavor that is sensitive to changes in monetary policy expectation. The final step in modeling interest rate markets in EA is to calibrate the single factor mean reversion interest rate models for the estimation of parameters of the model. The Vasicek model is represented as:

$d \dot{r}_{t}=\alpha\left(\beta-\dot{r}_{t}\right) d_{t}+\sigma d w_{t}$

Where $\alpha$ is speed of mean reversion, $\beta$ is the long term mean of 3 month by 3 month forward starting swaps, $\sigma d w_{t}$ is the instantaneous volatility with a Weiner process, $\dot{r}$ is the spot interest rate of 3 month by 3 month forward starting swaps and $\alpha\left(\beta-\dot{r}_{t}\right) d_{t}$ is the drift term.

\footnotetext{
${ }^{7}$ See James and Webber (2000) who list models as being the following types:

- The traditional one, two and multifactor equilibrium models known as affine term structure models. These include Gaussian affine models such as Vasicek and Hull-White and Steeley, where the model describes a process with constant volatility and models that have square root volatility such as Cox- Ingersoll - Ross. These models use constant parameters including a constant volatility and the actual parameters are calculated from actual data and implied volatilities which are obtained from exchange traded option contracts.

- Whole yield curve models such as Heath- Jarrow -Morton.

- Market models such as Jamshidian.

- Consol models such as Brennan and Schwartz.

No arbitrage models fit precisely with the observed term structure of the yield curve, thus the observed bond yields are in fact equal to the bond yields calculated by the model. The arbitrage free model is intended to be consistent with the currently observed zero coupon yield curve and the short rate drift rate is dependent on time, because the future average path taken by the short rate is determined by the shape of the initial yield curve. Some of these models include:

- Ho-Lee model

- Hull-White

- Black-Derman-Toy

- $\quad$ Black - Karasinki
}

\footnotetext{
${ }^{8}$ The period of study is from $2^{\text {nd }}$ June 2008 to $30^{\text {th }}$ September 2011 . The time period takes into account of the GFC of 2008 which at its peak witnessed the collapse of investment bank Lehman Brothers on $15^{\text {th }}$ September 2008 when it filed for Chapter 11 bankruptcy.
}

\footnotetext{
${ }^{9}$ Initial policy rate - China 1y PBOC Lending rate of 7.47\%, India RBI Repo yield of 7.75\%, S.Korea Overnight call rate of 5.0\%, Taiwan Discount rate of $3.5 \%$, Hong Kong HKMA Base rate of 3.5\%, Singapore Association of Banks of Singapore $3 \mathrm{~m}$ SIBOR rate of $1.25 \%$, Indonesia BI Reference rate of $8.25 \%$, Thailand BOT policy rate of 3.25\%, Malaysia BNM Overnight policy rate of 3.5\%, Philippines BSP overnight repo rate of $7.0 \%$.
} 
The Cox Ingersoll Ross model is represented as:

$$
d \dot{r}_{t}=\alpha\left(\beta-\dot{r}_{t}\right) d_{t}+\sigma \sqrt{\dot{r}_{t}} d w_{t}
$$

The parameters in the Cox Ingersoll Ross model are the same as with the Vasicek model with the exception of the instantaneous volatility which is $\sigma \sqrt{ } \dot{r}_{t} d w_{t}$.

In calibrating the single factor mean reversion interest rate models for estimation of parameters, this exercise uses a stochastic differential equation in the framework of Ornstein-Uhlenbeck process. The process involves:

$r_{i+1}=r_{i} e^{-\alpha \delta}+\beta\left(1-e^{-\alpha \delta}\right)+\sigma \sqrt{ } \frac{1-e^{-2 \alpha \delta}}{2 \alpha}$

Where the interest rates in the period ahead $r_{i+1}$ is determined by actual interest rates at period $r_{i}$ with respect to a mathematical constant of $e$ approximately equal to 2.71828 . This is adjusted to the speed of mean reversion parameter and the fixed time step of $\delta$. The fixed time step is measured as a single day divided by the 252 trading days in a year which is 0.00397 . The mean of the 3 month by 3 month forward starting swap $\beta$ is adjusted by the difference against the mathematical constant of 2.71828 that is powered to the mean reversion parameter and the time step. The stochastic differential equation takes into account of instantaneous volatility in the framework of the mathematical constant, the speed of mean reversion and the fixed time step. The relationship between $r_{i}$ and $r_{i+1}$ is linear with a normal random error of $\varepsilon_{\varepsilon}$ allowing the estimation of:

$$
r_{i+1}=\dot{\alpha} r_{i}+b+\varepsilon_{i}
$$

\subsection{Equation Specification Diagnostic}

From equation (4), interest rates in the period ahead $r_{i+1}$ is determined by actual interest rates at period $r_{i}$, the mean of the 3 month by 3 month forward starting swap $\beta$ and a normal random error of $\varepsilon_{\xi}$. Equation (4) is estimated using a linear square method and the random error of $\varepsilon_{\varepsilon}$ is tested for stability using the BreuschGodfrey serial correlation LM test. The residual from equations (4) is tested for heteroscedasticity to identify if estimated variance of the residuals are dependent on the values of the independent variables using the BreuschPagan-Godfrey test. To examine whether the parameters of the equation is stable across the sample period, the recursive residual is plotted with standard error bands of $+/-2.0$. Recursive residual within the band indicate periods of stability. Once it has been identified that there is no evidence of serial correlation and the equation specification is stable, the parameters from this equation are calibrated into the Ornstein-Uhlenbeck process, where:

$\dot{\alpha}=e^{-\alpha \delta}, b=\beta\left(1-e^{-\alpha \delta}\right)$ and standard deviation of $\varepsilon=\sigma \sqrt{\frac{1-e^{-2 \alpha \delta}}{2 \alpha}}$.

Rewriting this gives,

$\alpha=\frac{-\ln \dot{\alpha}}{\delta}, \beta=\frac{b}{1-\dot{\alpha}}$ and $\sigma=\operatorname{std} \cdot \operatorname{dev}\left(\varepsilon_{\mathrm{b}}\right) \sqrt{\frac{-2 \ln \dot{\alpha}}{\delta\left(1-\dot{\alpha}^{2}\right)}}$.

\subsection{Calibrating the Ornstein - Uhlenbeck process}

The final step in modelling interest rate markets in EA is calibrating the Ornstein-Uhlenbeck process by using the parameters that were estimated from equation (4) to find the values of $\alpha, \beta$ and $\sigma$ for both the single factor mean reversion interest rate models of Vasicek and Cox Ingersoll Ross.

This is obtained from rewriting:

$\alpha=\frac{-\ln \dot{\alpha}}{\delta}$,

$\beta=\frac{b}{1-\dot{\alpha}}$ and,

$\sigma=\operatorname{std} \cdot \operatorname{dev}\left(\varepsilon_{\xi}\right) \sqrt{\frac{-2 \ln \dot{\alpha}}{\delta\left(1-\dot{\alpha}^{2}\right)}}$.

\subsection{Drift Term of Vasicek and Cox Ingersoll Ross Models}

The framework for Vasicek and Cox Ingersoll Ross single factor mean reversion interest rate models indicate the drift term is a function of financial market related interest rates in the form of,

$\alpha\left(\beta-\dot{r}_{t}\right) d_{t}=f\left(d \dot{r}_{t}\right)$ 
By integrating this into a second order polynomial regression, the coefficient of $\varphi_{2}$ is obtained to reflect the inverse relationship, where

$\alpha\left(\beta-\dot{r}_{t}\right) d_{t}=\varphi_{0}+\varphi_{1} d \dot{r}_{t}+\varphi_{2} d \dot{r}_{t}^{2}+C$

and setting the intercept $\varphi_{0}=0$ the equation is transformed to,

$\alpha\left(\beta-\dot{r}_{t}\right) d_{t}=\varphi_{1} d \dot{r}_{t}+\varphi_{2} d \dot{r}_{t}^{2}+C$

The drift term captures behavioral aspect of agents in the financial market and shows the behavior for financial market related interest rates to either move up or down towards equilibrium. A negative coefficient $\varphi_{2}$ of the drift term generates the tendency for interest rates to move downwards towards equilibrium while a positive coefficient $\varphi_{2}$ of the drift term generates the tendency for interest rates to move upwards towards equilibrium

\section{(i) Serial Correlation and Heteroscedasticity Test}

\section{Findings}

Estimated $\dot{\alpha}$ parameter of equation (4) reflect financial market related interest rates $r_{i}$ influences interest rate behavior in a forward manner $r_{i+1}$, which is consistent with the behavior of financial market agents of taking into account of current behavior of interest rates in shaping their forward expectation of interest rates. Initial estimates of equation (4) shows strong evidence of serial correlation with the error term being correlated and the presence of heteroskedasticity where the error term has a different variance. In both instances the ordinary least squares assumption were violated, rendering equation (4) as not correctly specified and unstable. Omission of relevant explanatory variables may have been a factor, however in modeling imperfections in interest rate markets it is evident that the behavior of interest rate markets are subject to amplitude of randomness gaining admission into interest rate market, and these randomness is notable during the period of study which include the GFC of 2008. Rectifying serial correlation presence was done by taking into account of lagged periods of the residuals in the Breusch - Godfrey test. The lagged periods differed for each interest rate markets in EA. In the case of eliminating heteroskedasticity the Breusch - Pagan - Godfrey test increased the number of regressors against a second moment residual.

Following the rectification of serial correlation and heteroskedasticty, the stability of the equation improved based on chi-square $\left(x^{2}\right)$ values for the Breusch-Godfrey serial correlation LM test which show no evidence of serial correlation in the residuals, indicating non rejection of the null hypothesis of no serial correlation, and variance estimates of the residuals showing no sign of heteroscedasticity implying variance of the residual as constant (see Table 1).

Table 1 - Estimated parameters from equation (4)

$$
r_{i+1}=\dot{\alpha} r_{i}+b+\varepsilon_{\dot{c}}, \text { where } \dot{\alpha}=e^{-\alpha \delta}, b=\beta\left(1-e^{-\alpha \delta}\right) \text { and } \varepsilon_{i}=\sigma \sqrt{ } \frac{1-e^{-2 \alpha \delta}}{2 \alpha}
$$

\begin{tabular}{lccccc}
\hline & \multicolumn{1}{c}{$\dot{\alpha}^{*}$} & $\boldsymbol{b}$ & $\varepsilon^{* *}$ &.$p$-values $\left(\chi^{2}(1)\right)$ &.$p$-values $\left(\chi^{2}(2)\right)$ \\
\hline China & 0.9914 & 0.0198 & 0.1151 & 0.1390 & 0.3117 \\
India & 0.9961 & 0.0222 & 0.1447 & 0.2005 & 0.0417 \\
South Korea & 1.0009 & -0.0012 & 0.0490 & 0.1855 & 0.0020 \\
Taiwan & 1.0020 & -0.0005 & 0.0265 & 0.4212 & 0.3094 \\
Hong Kong & 0.9989 & 0.0028 & 0.0607 & 0.6763 & 0.0502 \\
Singapore & 0.9903 & 0.0127 & 0.0851 & 0.0970 & 0.2148 \\
Indonesia & 0.9303 & 0.5647 & 0.8363 & 0.0591 & 0.0801 \\
Thailand & 0.9962 & 0.0098 & 0.1000 & 0.0776 & 0.0524 \\
Malaysia & 0.9992 & 0.0023 & 0.0289 & 0.0610 & 0.3271 \\
Philippines & 0.9544 & 0.1876 & 0.3731 & 0.0844 & 0.1561 \\
\hline
\end{tabular}

Source: Author's calculation.

Notes: ${ }^{*}$ Significant at $1 \%$ and $5 \%$ t- stat critical values.

** To estimate $\varepsilon_{\varepsilon}$, the standard error of regression is used.

$p$-values $\left(\chi^{2}(1)\right)$ for Breusch-Godfrey serial correlation LM test. The $\chi^{2}$ estimates for Breusch-Godfrey serial correlation LM test are significant at critical values of $5 \%$.

$p$-values $\left(\chi^{2}(2)\right)$ for Breusch-Pagan-Godfrey heteroscedasticity test. The $\chi^{2}$ estimates for Breusch-Pagan-

Godfrey heteroscedasticity test are significant at critical values of 5\% 


\section{(ii) Recursive Residuals and Parameters Stability}

The recursive residuals that are within the $+/-2.0$ standard error bands suggest stability in the parameters of the equation but periods of instability for parameters of the equation were mostly concentrated during the early periods of GFC 2008 particularly in the months leading to the collapse of Lehman Brothers. Recursive residuals of the equation also indicate it is within the $+/-2.0$ standard error bands for all EA interest rate markets across the sample period with the exception of Indonesia which experienced recursive residuals breaching the $+/-2.0$ standard error band in the months leading to the collapse of Lehman Brothers and during the period of January to July 2010. (see Figure 1).

\section{Figure 1 - Recursive Residuals with +/- 2.0 Standard Error Bands}

China
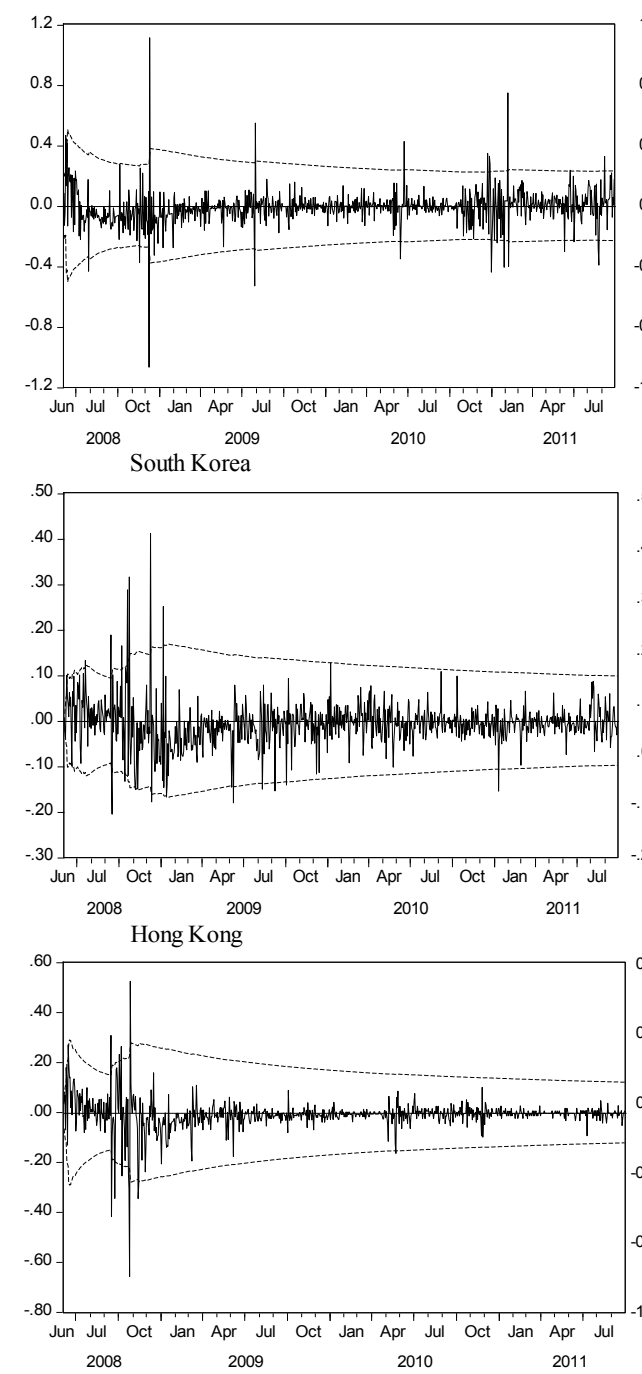

Indonesia

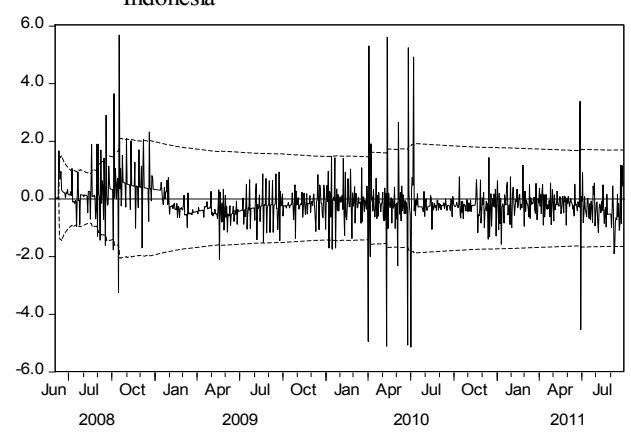

India

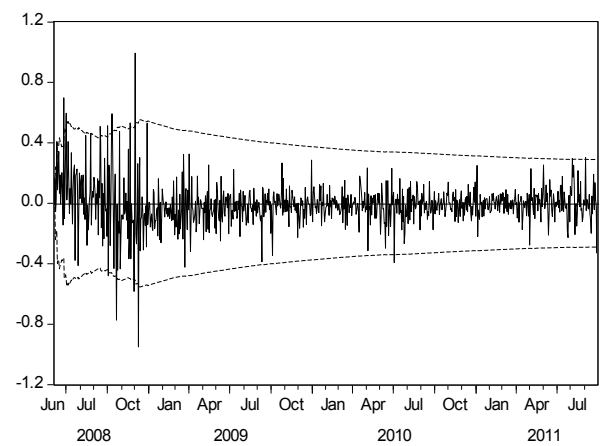

Taiwan
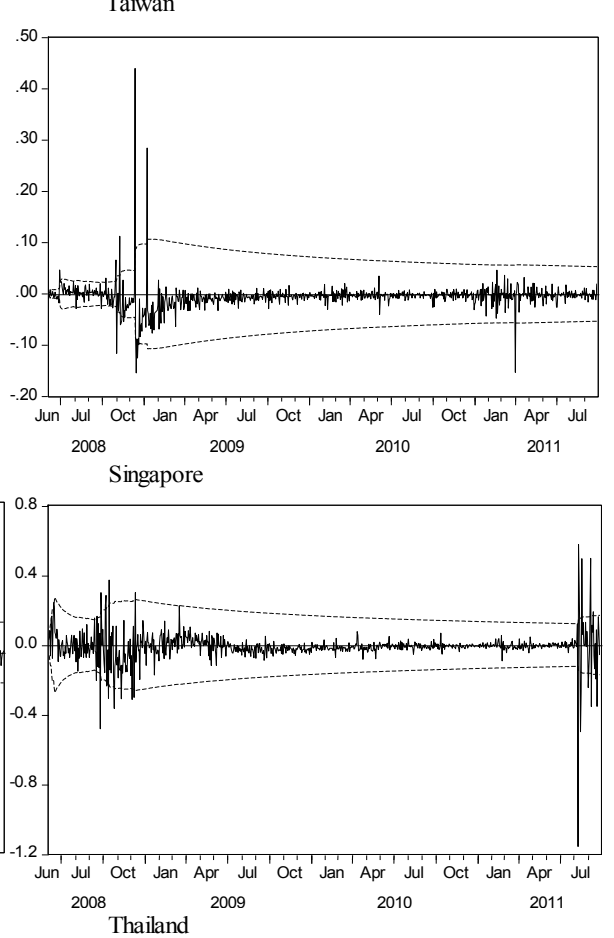

Thailand

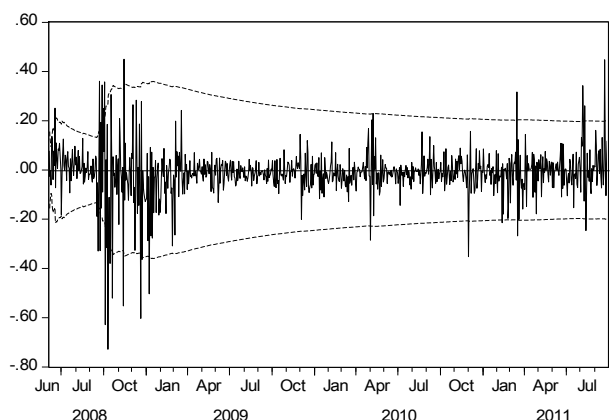



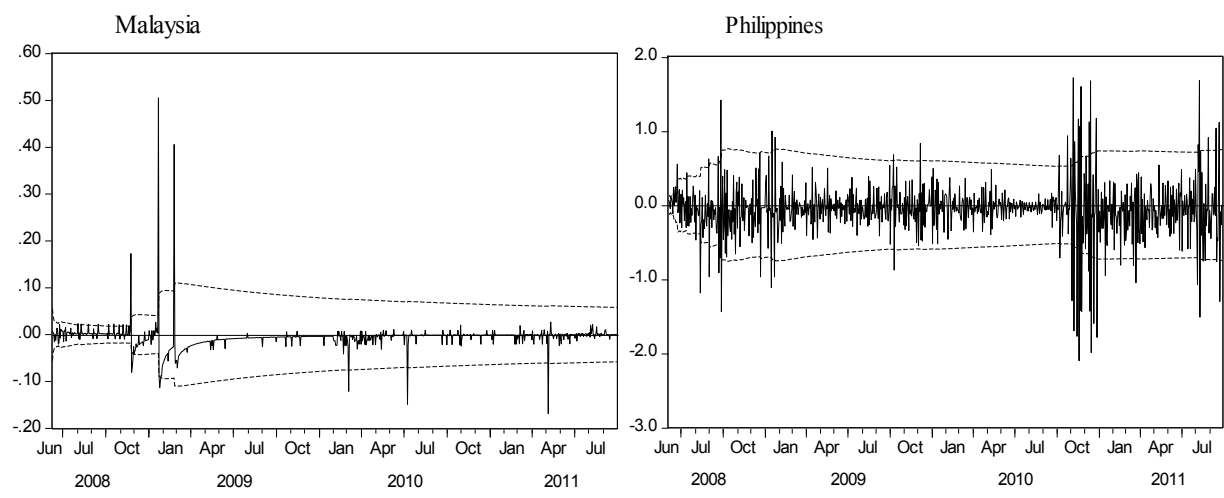

Source: Author's calculation

(iii)

\section{Mean Reversion of Interest Rates in Emerging Asia}

Estimates of the $\alpha$ coefficient (see Table 2) indicate the speed of mean reversion in single factor interest rate models for Indonesia and Philippines as weak. Weak mean reversion of interest rates towards the long term mean $\beta$ suggests high probability of agents in financial markets failing to interpret monetary policy signaling efficiently and financial market related interest rate unable to achieve equilibrium. In such cases the effectiveness monetary policy erodes as it departs from the objectives of central banks and financial regulators. In an environment of weak mean reversion of interest rates that is subject to external shocks, distortion in financial market related interest rate could be severe. Measures undertaken by central banks and financial regulators to correct this distortion using monetary policy could instead destabilize financial markets.

Table 2 - Estimated parameters ${ }^{10}$ from equation (1) and (2) of Vasicek model $d \dot{r}_{t}=\alpha\left(\beta-\dot{r}_{t}\right) d_{t}+\sigma d w_{t}$ and CIR $d \dot{r}_{t}=\alpha\left(\beta-\dot{r}_{t}\right) d_{t}+\sigma \sqrt{\dot{r}_{t}} d w_{t}$

\begin{tabular}{|c|c|c|c|c|c|}
\hline & $\alpha$ & $\beta$ & $\sigma d w_{t}$ & $\sigma \sqrt{ } \dot{r}_{t} d w_{t}$ & $\begin{array}{c}\text { Instantaneous Volatility relative intensity } \\
\text { between Vasicek and CIR model }\end{array}$ \\
\hline China & 2.1510 & 2.3319 & 1.7988 & 9.6150 & 7.8162 \\
\hline India & 0.9802 & 5.7441 & 2.3307 & 8.3721 & 6.4014 \\
\hline S.Korea & 2.1482 & 3.7732 & 2.2073 & 9.8715 & 7.6642 \\
\hline Taiwan & 0.5146 & 0.2922 & 0.3804 & 2.0328 & 1.6524 \\
\hline Hong Kong & 0.2706 & 2.6598 & 0.8902 & 4.7581 & 3.8679 \\
\hline Singapore & 2.4488 & 1.3192 & 1.3278 & 11.8762 & 10.5484 \\
\hline Indonesia & 18.1790 & 8.1106 & 13.8026 & 48.0524 & 34.2498 \\
\hline Thailand & 0.9446 & 2.6259 & 1.5810 & 8.7698 & 7.1888 \\
\hline Malaysia & 0.1763 & 3.3100 & 0.3426 & 1.8302 & 1.4876 \\
\hline Philippines & 11.7393 & 4.1204 & 6.0901 & 23.0184 & 16.9283 \\
\hline
\end{tabular}

Source: Author's calculation

Notes: The parameters estimated above are in $\%$ terms. Where $\alpha=\frac{-\ln \alpha}{\delta}, \beta=\frac{b}{1-\dot{\alpha}}$ and $\sigma=\operatorname{std} \cdot \operatorname{dev}\left(\varepsilon_{\varepsilon}\right) \sqrt{ } \frac{-2 \ln \dot{\alpha}}{\delta\left(1-\dot{\alpha}^{2}\right)}$.

In comparison to interest rate markets in Hong Kong and Singapore that uses the exchange rate as a monetary policy tool, the speed of mean reversion parameter in single factor interest rate models reflect mixed signals. Hong Kong which uses a currency board system with a pegged currency against the USD, the speed of mean reversion of interest rates is robust compared to Singapore. Hong Kong's ability to manage financial market liquidity using the currency board framework on a daily basis gives forth better response to the speed of mean reversion of interest rates to its long term mean. Singapore which decides monetary policy on a semiannual

${ }^{10}$ The parameters of $\alpha$ and $\beta$ are the same for both models with the difference being the instantaneous volatility. The speed of mean reversion and instantaneous volatility are parameters that provide inference on behavior of agents in the interest rate markets. 
basis in April and October each year has limited monetary policy meetings which expose the interest rates in financial markets to long lag periods between financial shocks and the appropriate policy response. The weak speed of mean reversion in single factor interest rate models for Singapore is not due to agents in financial markets failing to interpret monetary policy signaling efficiently but it's due to the slow response period by the central bank

In interest rate markets of China, India, South Korea and Taiwan, the speed of mean reversion parameter in single factor interest rate models is mixed. India and Taiwan reflect robustness compared to China and South Korea which shows the divergence in financial market agents' ability to interpret monetary policy signaling efficiently. Among interest rates markets in EA the speed of mean reversion parameter in single factor interest rate models for Malaysia is the most robust indicating financial market agents' ability to interpret monetary policy signaling efficiently and the rapid response period by the central bank during periods of financial market shocks.

\section{(iv) Instantaneous Volatility in Emerging Asia Interest Rate Markets}

The instantaneous volatility ( $\sigma d w_{t}$ in Vasicek model and $\sigma \sqrt{r_{t}} d w_{t}$ in Cox Ingersoll Ross model) measures instant by instant the amplitude of randomness gaining admission into interest rate markets. Though elevation of instantaneous volatility was observed in both interest rate models, the elevation was more in the Cox Ingersoll Ross model compared to the Vasicek model in all ten EA interest rate markets (see Table 2). The relative intensity of instantaneous volatility between both models is modest for Taiwan and Malaysia compared to Indonesia and Philippines. Increased randomness penetrating the interest rate markets of Indonesia and Philippines is due to the weak monetary policy signaling effect which dilutes information flow from central banks' to agents in the financial market.

In comparison between Singapore and Hong Kong which adopt the exchange rate as a monetary policy tool, instantaneous volatility was higher for Singapore under both interest rate models. The relative intensity of instantaneous volatility for Singapore was also excessive compared to Hong Kong. A factor that belies this difference is the ability to manage financial market liquidity. In the case of Hong Kong, the framework of the currency board is integrated to financial market liquidity condition which is managed on a daily basis to keep the currency peg intact. Singapore on the other hand though manages financial market liquidity conditions using money market operations, the link between financial market liquidity and its currency policy has no direct influence.

The drift function $\alpha\left(\beta-\dot{r}_{t}\right) d_{t}$ in all ten EA interest rate markets reflect negative coefficient $\varphi_{2}$ (see Table 3) Financial market related interest rates are more likely to move downwards towards equilibrium rather than upwards. This signals financial market expectations of monetary policy easing instead of tightening.

Table 3 - Coefficient $\beta$ and $\varphi_{2}$

\begin{tabular}{lcc}
\hline & $\beta$ & $\varphi_{2}$ \\
\hline China & 2.3319 & -0.745 \\
India & 5.7441 & -0.146 \\
S.Korea & 3.7732 & -0.469 \\
Taiwan & 0.2922 & -0.077 \\
Hong Kong & 2.6598 & -0.522 \\
Singapore & 1.3192 & -2.107 \\
Indonesia & 8.1106 & -1.924 \\
Thailand & 2.6259 & -0.401 \\
Malaysia & 3.3100 & -0.072 \\
Philippines & 4.1204 & -2.456 \\
\hline
\end{tabular}

Source: Author's calculation using excel spreadsheet

Notes: $\beta$ is the mean of implied modeled interest rates and $\varphi_{2}$ is the coefficient of the drift term, Estimates of $\beta$ and $\varphi_{2}$ from equation (4.7) and are in $\%$ terms.

Singapore and Philippines have the largest negative coefficient of the drift term which suggests financial markets in these two economies anticipate aggressive monetary policy easing. In the case of Singapore, monetary policy decision on a semiannual basis exposes agents in the interest rate market to long lag period between financial shocks and appropriate policy response. The delay in policy response and the lack of it between official monetary policy meetings attributes to the large negative coefficient of the drift term Consistent with a negative coefficient $\varphi_{2}$, the drift term $\alpha\left(\beta-\dot{r}_{t}\right) d_{t}$ and financial market related interest rates $\dot{r}_{t}$ is inversely related as the curve is downward sloping in all ten interest rate markets of EA (see Figure 2). 
Figure 2 -Negative Sloped Drift Term
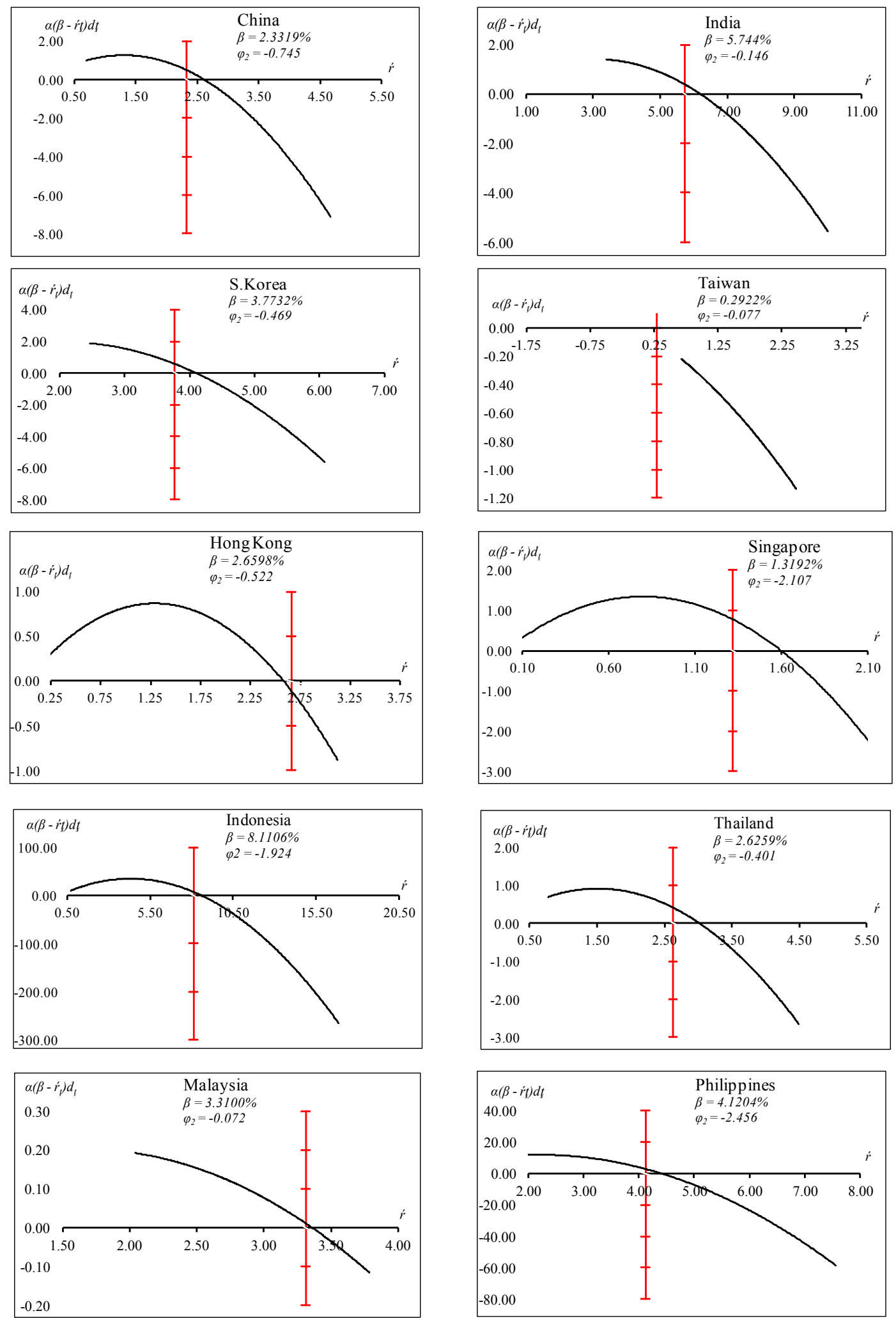


\section{Implied Vasicek and Cox Ingersoll Ross Interest Rates}

With the identification of parameters of the single factor mean reversion interest rate models, the variables are applied into a simulation mode ${ }^{11}$ to obtain the implied Vasicek and Cox Ingersoll Ross interest rates (see Figure 3). The simulation involves four main parameters which include the initial policy rate at the beginning of the analysis, the speed of mean reversion, the mean of financial market related interest rates which is the forward starting swaps in this exercise, the instantaneous volatility and the fixed time step which is measured as a single day divided by the 252 trading days in a year which is 0.00397 .

\section{Figure 3 Implied Vasicek and Cox Ingersoll Ross Single Factor Mean Reversion Interest Rates of Emerging Asia.}
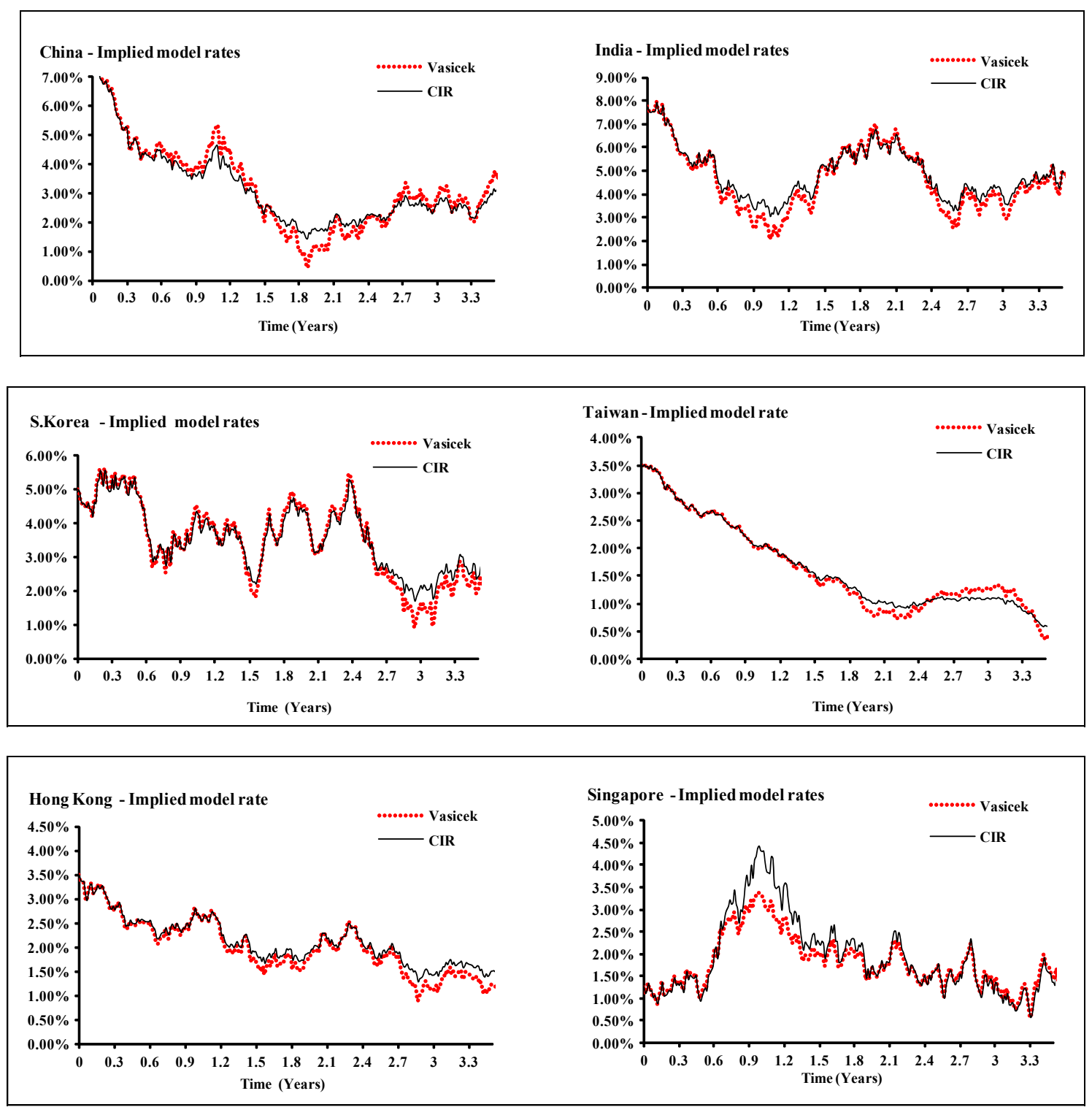

\footnotetext{
${ }^{11}$ The simulation model is applied once the parameters of the Vasicek and Cox Ingersoll Ross models have been identified. The simulation takes into account the period of study between June 2008 to September 2011, which is 3.3 years, $\alpha$ the speed of mean reversion, $\beta$ the long term mean of 3 month by 3 month forward starting swaps, $\sigma d w_{t}$ the instantaneous volatility with Weiner process for Vasicek model and $\sigma \sqrt{r_{t}} d w_{t}$ for Cox Ingersoll Ross model. Each parameter is applied into the excel spreadsheet to churn out the implied modeled rates for Vasicek and Cox Ingersoll Ross models.
} 

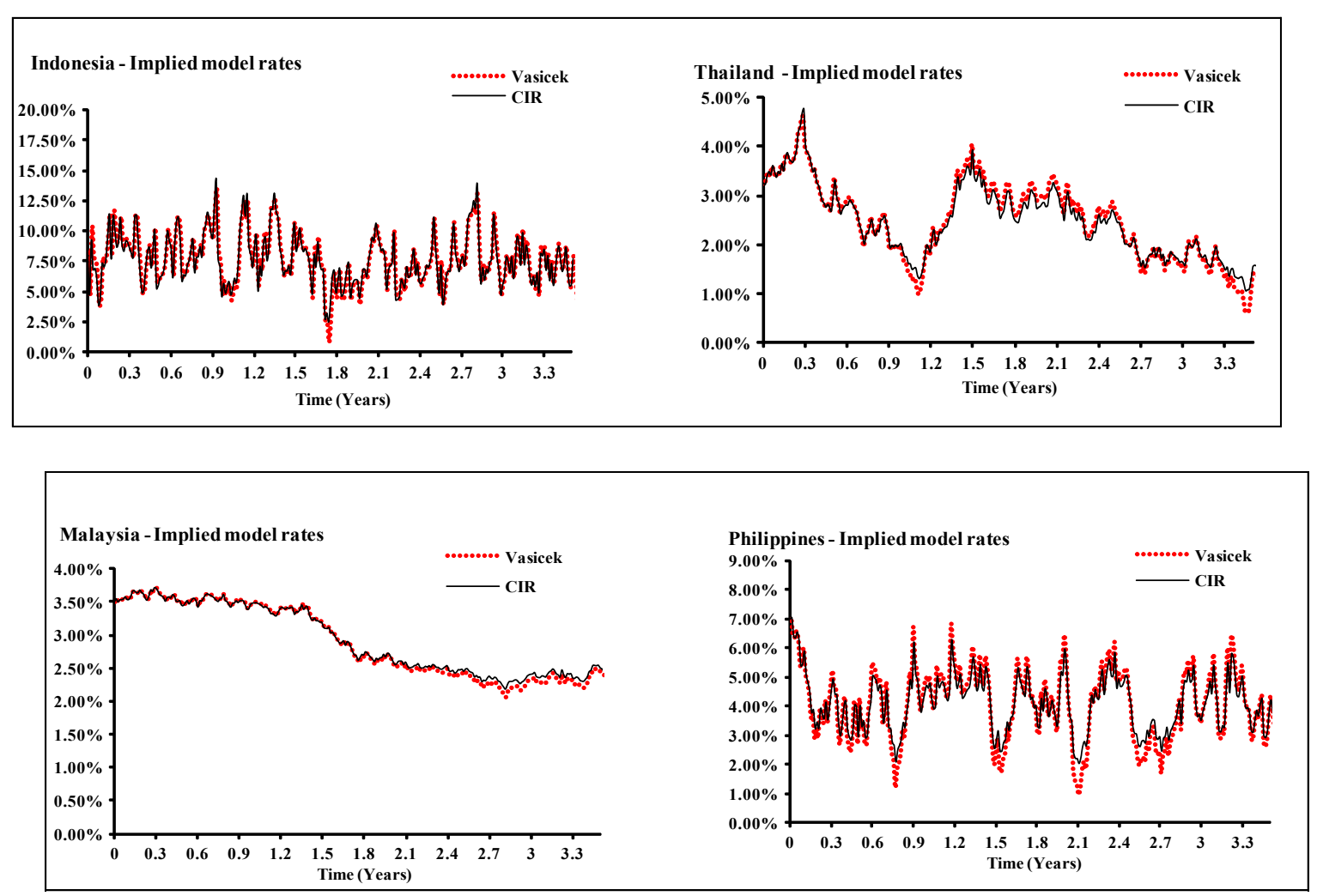

Source: Author's calculation

\section{Concluding remarks}

Weak mean reversion of interest rates towards the long term mean suggests high probability of agents in financial markets failing to interpret monetary policy signaling efficiently and financial market related interest rate unable to achieve equilibrium. In such cases the effectiveness monetary policy erodes as it departs from the objectives of central banks and financial regulators. In an environment of weak mean reversion of interest rates that is subject to external shocks, distortion in financial market related interest rate could be severe. Measures undertaken by central banks and financial regulators to correct this distortion using monetary policy could instead destabilize financial markets. Increased randomness penetrating interest rate markets is due to the weak monetary policy signaling effect which dilutes information flow from central banks' to agents in the financial market.The negative drift function in all ten EA interest rate markets reflect financial market related interest rates are more likely to move downwards towards equilibrium rather than upwards. This signals financial market expectations of monetary policy easing instead of tightening.

\section{References}

[1]. Acharya, V.V., and D. Skeie., 2011. A model of liquidity hoarding and term premia in inter-bank markets. Journal of Monetary Economics 58, 436-447

[2]. Ashraf, N., Camerer, C. F. and Loewenstein, G., 2005. Adam Smith, behavioral economist. Journal of Economic Perspectives. Vol. $19,131-45$

[3]. Al-Zoubi, H.A., 2009. Short-term spot rate models with nonparametric deterministic drift. The Quarterly Review of Economics and Finance 49, 731-747.

[4]. Cox, J.C., Ingersoll, J.E. and Ross, S., 1985. A theory of the term structure of interest rates. Econometrica, 385-407.

[5]. Doob, J.L., 1942. The Brownian movement and stochastic equations. Annals of Mathematics 43, 351-369.

[6]. G. E. Uhlenbeck and L. S. Ornstein.,1930. On the theory of Brownian Motion. Phys.Rev 36, 823-841.

[7]. Janczura, Orzeł and Wyłomańska., 2011. Subordinated $\alpha$-stable Ornstein-Uhlenbeck process as a tool for financial data description. Physica A 390, 4379-4387.

[8]. James, J., Webber, N., Interest Rate Modeling, Wiley 2000, 444

[9]. Szyszka. A.,2011. The genesis of the 2008 global financial crisis and challenges to the neoclassical paradigm of finance. Global Finance Journal 22, 211-216.

[10]. Tak. K. S., 2010. Bond pricing under a Markovian regime-switching jump-augmented Vasicek model via stochastic flows. Applied Mathematics and Computation 216, 3184-3190

[11]. Vasicek, O., 1977. An equilibrium characterization of the term structure. Journal of Financial Economics, 177-188.

[12]. Zeytun, S., \& Gupta, A., 2007. A Comparative Study of the Vasicek and the CIR Model of the Short Rate. Kaiserslautern. Germany: ITWM. 